\title{
DESKRIPSI PENGGUNAAN ZAT PEWARNA SINTETIS RHODAMIN B PADA MAKANAN JAJANAN JELLY YANG DIJUAL DI SEKOLAH DASAR NEGERI DI KECAMATAN TAMAN KABUPATEN PEMALANG TAHUN 2017
}

\author{
Stella Evangelista Liwe ${ }^{*}$, Arif Widyanto ${ }^{* *}$ ) \\ Jurusan Kesehatan Lingkungan, Politeknik Kesehatan Kemenkes Semarang, \\ Jl.Raya Baturaden KM 12 Purwokerto, Indonesia
}

\begin{abstract}
Abstrak
Makanan yang memenuhi standar kesehatan, yakni makanan yang bebas dari zat-zat berbahaya seperti pewarna sintetis, pengawetan, serta pemanis buatan yang dilarang. Jelly merupakan salah satu jajanan yang digemari anak-anak karena bentuk dan warna yang menarik. Hal ini sering dimanfaatkan pedagang untuk mengejar keuntungan dengan menggunakan zat pewarna sintetis agar warna makanan terlihat lebih menarik. Penelitian ini bertujuan untuk memeriksa ada tidaknya zat pewarna sintetis rhodamin B, mendeskripsikan faktor-faktor yang mempengaruhi para penjual bebas menjual jelly yang mengandung rhodamin B dan memeriksa kualitas jelly secara organoleptik.

Metode penelitian adalah deskriptif yaitu dengan melakukan observasi, wawancara, pemeriksaan rhodamin B pada jelly dan pemeriksaan kualitas jelly secara organoleptik. Jumlah sampel dalam penelitian ini adalah 15 sampel jelly.

Berdasarkan hasil yang didapat, 3 dari 15 sampel yang diperiksa positif rhodamin B. Pengetahuan Mrs C,D,E dalam kategori sangat baik (80\%). Mrs J,K,M,N,O dalam kategori baik (57,1\% dan 71,4\%) dan Mrs A,B,F,G,H,I,L dalam kategori cukup (42,8\%). Perilaku Mrs A,C,D,E,M,N,O dalam kategori sangat baik (83,3\%). Mrs F,G,I,K,L dalam kategori baik (66,6\%), Mrs H,B dalam kategori cukup (50\%) dan Mrs $J$ dalam kategori kurang (33,3\%). Ketersediaan zat pewarna sintetis Mrs A,B,C,D,H,J dalam kategori mudah dan Mrs E,F,G,I,K,L,M,N,Odalam kategori tidak mudah. Mrs A yang mendapatkan penyuluhan sangat baik sisanya dalam kategori baik. Mrs A yang mendapatkan pengawasan sangat baik sisanya dalam kategori baik.Dari 15 sampel ada 4 jelly yang berwarna merah mencolok.

Kesimpulan penelitian adalah terdapat 3 sampel jelly positif rhodamin B dari 15 sampel yang diperiksa di Sekolah Dasar Negeri di Kecamatan Taman Kabupaten Pemalang. Disarankan agar masyarakat lebih meningkatkan pengawasan terhadap anak, untuk pedagang yang belum memiliki surat perijinan dagang sebaiknya mengurus surat perijinan dagang, untuk petugas kesehatan disarankan agar meningkatkan penyuluhan dan pengawasan dan untuk pihak sekolah sebaiknya memberikan pengertian kepada siswanya agar lebih berhati-hati dalam membeli makanan serta memberi peraturan untuk berdagang di lingkungan sekolah harus memiliki ijin dari Dinas Kesehatan.
\end{abstract}

Kata kunci:rhodamin B, makanan jelly, sekolah dasar, kesehatan lingkungan

\begin{abstract}
Description Of The Use Of Synthetic Dyes Of Rhodamin B On Jelly Food Snacks For Sale In State Elementary School In Subdistrict Taman Of All District Pemalang.Foods that satisfy health standards, is a food free of hazardous substances such as synthetic dyes, preservation, and artificial sweeteners are prohibited. Jelly is one of the favorite snacks of children because of the attractive shapes and colors. It is often used by traders to pursue profit by using synthetic dyes to make the color of food look more attractive. The purpose of this study was to examine whether there is content rhodamin B, describe the factors that influence traders to sell jelly using rhodamin B and check the quality jelly organoleptically.
\end{abstract}


The research use descriptive method to carry out observation, interview, rhodamin B examination on jelly and checks of quality jelly organoleptically. The number of samples in this study were fifteen samples of jelly.

Based on the results obtained, three of fifteen samples positive rhodamin $B$. Knowledge of Mrs $C, D, E$ in very good category (100\%). Mrs. J, K, $M, N$, $O$ in good category $(57,1 \%$ and $71,4 \%)$ and Mrs $A, B, F, G$, $H, I, L$ in enough category (42,8\%). The behavior of Mrs A, C, D, E, M, N, O is in very good category (83,3\%). Mrs F, G, I, K, L in good category (66,6\%), Mrs H, B in enough category (50\%) and Mrs $J$ in the less category $(33,3 \%)$. The availability of synthetic dyes of Mrs $A, B, C, D, H, J$ in the easy category and Mrs E, F, G, I, K, L, M, N, O in categories is not easy. Mrs. A who gets excellent extension of the rest in either category. Mrs A gets excellent scrutiny of the rest in either category. Of the 15 samples there are 4 jelly that is bright red.

The conclusion of the research is three samples positive rhodamin $B$ from fifteen samples examined at State Elementary School in Subdistrict Taman of all District Pemalang.It is suggested that the public should improve supervision of children, for traders who don't have a business license must take care of the permit letter, for health workers it is advisable to improve counseling and supervision and for the school should give understanding to the students to be more careful in buying food and provide regulations to trade in the school environment must have a license from the Department of Health.

Keywords:rhodamin B, jelly food, primary school, environmental health

\section{Pendahuluan}

Tujuan pembangunan bidang kesehatan sebagaimana tercantum dalam Undang-undang Nomor 36 tahun 2009 tentang kesehatan ayat 3 yaitu pembangunan kesehatan bertujuan untuk meningkatkan kesadaran, kemauan, dan kemampuan hidup sehat bagi setiap orang agar terwujud derajat kesehatan masyarakat yang setinggi-tingginya, sebagai investasi bagi pembangunan sumber daya manusia yang produktif secara sosial dan ekonomis. Pembangunan bidang kesehatan dapat dilaksanakan melalui kegiatan antara lain perbaikan gizi, pengamanan makanan dan minuman dari bahanbahan terlarang, kesehatan lingkungan dan lain-lain.

Peraturan Mentri Kesehatan RI No. 329/Menkes/XII/76 tentang Produksi dan Peredaran makanan menyebutkan, yang dimaksud dengan zat adiktif makanan adalah bahan yang ditambahkan dan dicampurkan sewaktu proses pengolahan makanan untuk meningkatkan mutu. Termasuk didalamnya adalah pewarna, penyedap rasa dan aroma, pengawet, dan pengental. Menurut SNI 01-751-2006 mengenai bahan tambahan pangan, pengertian bahan tambahan pangan adalah bahan yang ditambahkan ke dalam pangan untuk memengaruhi sifat atau bentuk pangan atau produk pangan.

${ }^{*}$ E-mail: stella.liwe12@gmail.com

${ }^{* *}$ E-mail: arifwidyanto74@yahoo.com
Makanan yang sehat tentunya makanan yang memenuhi standar kesehatan, yakni makanan yang bebas dari zat-zat berbahaya seperti pewarna sintetis, pengawetan, serta pemanis buatan yang dilarang penggunaannya dalam makanan. Pemakaian bahan pewarna pangan sintetis dalam pangan walaupun mempunyai dampak positif bagi produsen dan konsumen, diantaranya dapat membuat suatu pangan lebih menarik, meratakan warna pangan, dan mengembalikan warna dari bahan dasar yang hilang atau berubah selama pengolahan. Beberapa penelitian telah dibuktikan bahwa zat pewarna tekstil yang tidak diizinkan akan bersifat racun bagi manusia sehingga dapat membahayakan kesehatan konsumen, dan senyawa tersebut mempunyai peluang dapat menyebabkan kanker pada hewanhewan percobaan (Wisnu Cahyadi, 2008, h.17)

Permenkes R.I Nomor 033 tahun 2012 tentang Bahan Tambahan Pangan, ada beberapa tambahan bahan yang tidak diperbolehkan untuk makanan antara lainRhodamin B (pewarna merah), Methanyl Yellow (pewarna kuning), Dulsin (pemanis sintesis) dan Pottasium Bromat (pengeras). Rhodamin $B$ adalah pewarna merah terang sering ditemukan di pangan dan kosmetik dan bersifat racun serta karsinogenik. Rhodamin $B$ bahaya jika tertelan, terhirup, atau terserap oleh kulit. Penggunaan rhodamin $B$ dapat menyebabkan iritasi saluran pernapasan dan merupakan zat karsinogenik (dapat menyebabkan kanker). Alasan penggunaan pewarna ini adalah untuk memperbaiki warna merah yang berkurang akibat penambahan bahan lain (Butarbutar, 2007). 
Hasil survey Badan Pengawas Obat dan Makanan tahun 2015 menunjukkan hampir separuh atau $44 \%$ jajanan anak yang dijual pedagang kaki lima tidak sehat dan mengandung zat adiktif. Direktur Pengawasan Produk dan Bahan Berbahaya BPOM Mustofa mengatakan ada empat urutan jajanan kaki lima yang paling berbahaya. Nomor satu adalah es, kedua sirup, ketiga jelly dan keempat adalah bakso. (Suryo Wibowo, 2015, h.1)

Jelly merupakan salah satu jajanan yang sangat digemari anak-anak karena mempunyai bentuk dan warna yang menarik. Hal ini yang sering dimanfaatkan pedagang untuk mengejar keuntungan dengan menggunakan zat pewarna sintetis agar warna makanan terlihat lebih menarik. Hasil pemeriksaan Kantor Ketahanan Pangan Kabupaten Pemalang pada tanggal 19 Februari 2016 ditemukan beberapa jajanan termasuk jajanan jelly di Sekolah Dasar Negeri wilayah Kecamatan Warungpring Kabupaten Pemalang positif mengandung zat pewarna sintetis rhodamin $B$. Kecamatan Taman mempunyai 74 Sekolah Dasar Negeri dan jumlah tersebut terbanyak seKabupaten Pemalang dan Kecamatan Taman terletak dipusat kota sehingga akses terhadap jajanan yang mengandung bahan tambahan pangan tertentu sangat mudah.

Permasalahan pada penelitian ini adalah :

a. Apakah ada kadar zat pewarna sintetik Rhodamin $B$ yang terdapat pada makanan jajanan jelly yang dijual di sekolah dasar negeri di Kecamatan Taman Kabupaten Pemalang tahun 2017 ?

b. Apakah faktor-faktor yang mempengaruhi para penjual jajanan bebas menjual jajanan jelly yang mengandung zat pewarna yang tidak diperbolehkan untuk makanan jajanan di sekolah dasar negeri di Kecamatan Taman Kabupaten Pemalang tahun 2017 ?

c. Bagaimana makanan jajanan jelly yang dijualdi sekolah dasar negeri di Kecamatan Taman Kabupaten Pemalang tahun 2017 ?

Tujuan dari Penelitian ini adalah :

a. Memeriksa ada tidaknya zat pewarna sintetik Rhodamin B pada makanan jajanan jelly yang dijual di sekitar wilayah Kecamatan Taman Kabupaten Pemalang tahun 2017

b. Mendeskripsikan faktor-faktor yang mempengaruhi para penjual bebas menjual makanan jajanan jelly yang mengandung zat pewarna yang tidak diperbolehkan untuk makanan jajanan di sekolah dasar negeri di Kecamatan Taman Kabupaten Pemalang tahun 2017

c. Memeriksa kualitas secara organoleptik makanan jajanan jelly yang dijual di sekolah dasar negeri di Kecamatan Taman Kabupaten Pemalang tahun 2017

\section{Metode}

Penelitian ini merupakan penelitian observasional yaitu dengan maksud untuk mengetahui ada tidaknya kadar zat pewarna sintetis rhodamin B pada makanan jajanan jelly yang dijual di sekolah dasar negeri di Kecamatan Taman Kabupaten Pemalang.

\section{Hasil dan Pembahasan}

Penelitian ini dilakukan di 15 Sekolah Dasar Negeri Kecamatan Taman Kabupaten Pemalang. Kecamatan Taman merupakan Kecamatan dengan desa paling banyak dibandingkan dengan kecamatan lainnya. Kecamatan Taman memiliki total 74 Sekolah Dasar Negeri dan 2 Sekolah Dasar Swasta. Jarak Kecamatan Taman dengan Ibukota Kabupaten adalah $5 \mathrm{Km}$. Tinggi dari permukaan air laut yaitu 6 m sedangkan Luas wilayah kecamatan Taman adalah $67,41 \mathrm{Km}^{2}$ dengan pembagian luas lahan sawah 36,35 $\mathrm{Km}^{2}$ dan luas lahan daratan 31,06 $\mathrm{Km}^{2}$. Kecamatan Taman terdiri dari 19 Desa dan 2 Kelurahan. Jumlah dusun di Kecamatan Taman ada 105, memiliki 176 Rukun warga (RW) dan 800 Rukun Tetangga (RT). Ibukota Kecamatan Taman adalah Desa Banjardawa. Letak Kecamatan Taman tidak terlalu jauh dengan Ibukota Kabupaten, hal tersebut membuat akses untuk memenuhi keperluan sehari-hari tidaklah sulit dan itu menguntungkan bagi pedagang yang ingin membeli bahan-bahan untuk dagangannya. Transportasi di Kecamatan Taman pun tidaklah sulit karena masih dalam jangkauan angkutan umum.

Tabel 4.1 Hasil Pemeriksaan Rhodamin B di Laboratorium

\begin{tabular}{lccc}
\hline No & $\begin{array}{c}\text { Nama } \\
\text { Sampel }\end{array}$ & Jenis Sampel & Hasil \\
\hline 1 & Jelly 01 & Gel & Negatif \\
2 & Jelly 02 & Gel & Positif \\
3 & Jelly 03 & Gel & Negatif \\
4 & Jelly 04 & Gel & Negatif \\
5 & Jelly 05 & Gel & Negatif \\
6 & Jelly 06 & Gel & Negatif \\
7 & Jelly 07 & Gel & Negatif \\
8 & Jelly 08 & Gel & Positif \\
9 & Jelly 09 & Gel & Negatif \\
10 & Jelly 10 & Gel & Positif \\
11 & Jelly 11 & Gel & Negatif \\
12 & Jelly 12 & Gel & Negatif \\
13 & Jelly 13 & Gel & Negatif \\
14 & Jelly 14 & Gel & Negatif \\
15 & Jelly 15 & Gel & Negatif \\
\hline
\end{tabular}


Pengambilan sampel jelly dilakukan pada tanggal 22 Mei 2017 di Sekolah Dasar Negeri Kecamatan Taman Kabupaten Pemalang didapatkan 15 sampel dengan pedagang yang berbeda. Pemeriksaan sampel dilakukan pada tanggal 23 Mei 2017 di Laboratorium Kesehatan Kabupaten Pemalang. Pemeriksaan dilakukan pada tanggal 23 Mei 2017 dikarenakan penanggung jawab bagian pemeriksaan di Laboratorium Kesehatan Kabupaten Pemalang berhalangan hadir sehingga pemeriksaan diundur dan berhubung sampel tersebut adalah jelly serta parameter yang diperiksa adalah zat pewarna rhodamin $B$ maka sampel dapat disimpan terlebih dahulu didalam lemari pendingin (kulkas) untuk sementara waktu sampai dilakukan pemeriksaan.

Hasil survey 18 pedagang yang menjual jelly di Sekolah Dasar Negeri Kecamatan Taman Kabupaten Pemalang didapatkan 15 sampel dengan pedagang yang berbeda. Sampel jelly yang diambil yaitu jelly yang berwarna merah atau merah mencolok dan tidak bermerek. Selanjutnya dibawa ke Laboratorium Kesehatan Kabupaten Pemalang. Dalam penelitian ini diambil 15 sampel dari 18 pedagang yang tersebar di 15 desa dan masingmasing desa diambil 1 sampel jelly yang berwarna merah.

Berdasarkan pemeriksaan dengan menggunakan metode kolorimetri yang dilakukan Laboratorium Kesehatan Kabupaten Pemalang menunjukkan bahwa dari 15 sampel jelly ada 3 sampel positif rhodamin $B$ sehingga makanan tersebut tidak aman untuk dikonsumsi. Menurut Peraturan Menteri Kesehatan nomor 033 tahun 2012 tentang Bahan Tambahan Pangan dan Bahan Berbahaya yang dilarang penggunaannya dalam makanan maka 15 jelly yang sudah diteliti 3 tidak memenuhi peraturan tersebut.

Rhodamin $B$ adalah zat pewarna sintetis yang tidak boleh digunakan dalam makanan dan minuman karena merupakan pewarna tekstil. Rhodamin $B$ memiliki kandungan logam berat yang cukup banyak dan tinggi. Efek negatif yang ditimbulkan antara lain iritasi lambung, alergi, bersifat karsinogenik (menyebabkan kanker), dan bersifat mutagen (menyebabkan perubahan fungsi sel atau jaringan), serta orang yang mengkonsumsinya akan muntah, diare bercampur darah, kencing bercampur darah, dan kematian yang disebabkan adanya kegagalan peredaran darah. Bila menguap di udara, berupa gas yang tidak berwarna, dengan bau tajam menyesakkan, sehingga merangsang hidung, tenggorokan, dan mata (Depkes RI,2007).

Tabel 4.2 Pengetahuan Pedagang Jelly

\begin{tabular}{lll}
\hline No & Nama Pedagang & Pengatahuan(\%) \\
\hline 1 & Mrs A & 42,8 (Cukup)
\end{tabular}

\begin{tabular}{lll}
2 & Mrs B & 42,8 (Cukup) \\
3 & Mrs C & 100 (sangat Baik) \\
4 & Mrs D & 100 (Sangat Baik) \\
5 & Mrs E & 100 (Sangat Baik) \\
6 & Mrs F & 42,8 (Cukup) \\
7 & Mrs G & 42,8 (Cukup) \\
8 & Mrs H & 42,8 (Cukup) \\
9 & Mrs I & 42,8 (Cukup) \\
10 & Mrs J & 57,1 (Baik) \\
11 & Mrs K & 57,1 (Baik) \\
12 & Mrs L & 42,8 (Cukup) \\
13 & Mrs M & 57,1 (Baik) \\
14 & Mrs N & 71,4 (Baik) \\
15 & Mrs O & 71,4 (Baik) \\
\hline
\end{tabular}

Berdasarkan tabel 4.2 dapat dilihat bahwa pengetahuan pedagang jelly hanya ada 3 pedagang yaitu Mrs C, Mrs D dan Mrs E yang memiliki pengetahuan sangat baik dengan prosentase $100 \%$. Hal ini dikarenakan pedagang mengetahui tentang zat pewarna, mengetahui zat pewarna alami, mengetahui zat pewarna sintetis, mengetahui zat pewarna sintetis yang tidak diizinkan ada dalam makanan, mengetahui ciri-ciri jajanan yang mengandung zat pewarna yang tidak diizinkan, mengetahui tanda-tanda orang keracunan akibat zat pewarna serta mengetahui tentang bahaya zat pewarna sintetis yang tidak diizinkan.

Kemudian ada 5 pedagang yang memiliki pengetahuan baik yaitu Mrs J, Mrs K dan Mrs M dengan prosentase 57,1 \% sedangkan Mrs N dan Mrs O dengan prosentase $71,4 \%$. Dari item pengetahuan yang tersedia dalam kuesioner Mrs J, Mrs K dan Mrs $M$ tidak mengetahui ciri-ciri jajanan yang mengandung zat pewarna yang tidak diizinkan, tidak mengetahui tanda-tanda orang keracunan akibat zat pewarna serta tidak mengetahui tentang bahaya zat pewarna sintetis yang tidak diizinkan, sedangkan Mrs $\mathrm{N}$ dan Mrs $\mathrm{O}$ tidak mengetahui tanda-tanda orang keracunan akibat zat pewarna serta tidak mengetahui tentang bahaya zat pewarna sintetis yang tidak diizinkan.

Sisanya 7 pedagang memiliki pengetahuan cukup yaitu Mrs A, Mrs B, Mrs F, Mrs G, Mrs H, Mrs I dan Mrs L dengan prosentase 42,8. Hal ini dikarenakan dari item pengetahuan yang tersedia dalam kuesioner pedagang tidak mengetahui zat pewarna sintetis yang tidak diizinkan ada dalam makanan, tidak mengetahui ciri-ciri jajanan yang mengandung zat pewarna yang tidak diizinkan, tidak mengetahui tanda-tanda orang keracunan akibat zat pewarna serta tidak mengetahui tentang bahaya zat pewarna sintetis yang tidak diizinkan. 
Pedagang yang mempunyai pengetahuan cukup sebaiknya lebih meningkatkan pengetahuan agar menjadi baik atau bahkan sangat baik sehingga pedagang tidak hanya menjual dagangannya tetapi juga menerapkan pengetahuannya pada makanan jajanan yang ia jual. Ada beberapa alasan yang menyebabkan masih banyaknya bahan tambahan yang telah dilarang tetapi tetap digunakan oleh pedagang, salah satunya adalah kurangnya pengetahuan pedagang tentang adanya bahan tambahan makanan yang dilarang penggunaannya untuk makanan (Alsuhendra \& Ridawati, 2013).

Tabel 4.3 Perilaku Pedagang Jelly

\begin{tabular}{lll}
\hline No & Nama Pedagang & Perilaku(\%) \\
\hline 1 & Mrs A & 83,3 (Sangat Baik) \\
2 & Mrs B & 50 (Cukup) \\
3 & Mrs C & 83,3 (Sangat Baik) \\
4 & Mrs D & 83,3 (Sangat Baik) \\
5 & Mrs E & 83,3 (Sangat Baik) \\
6 & Mrs F & 66,6 (Baik) \\
7 & Mrs G & 66,6 (Baik) \\
8 & Mrs H & 50 (Cukup) \\
9 & Mrs I & 66,6 (Baik) \\
10 & Mrs J & 33,3 (Kurang) \\
11 & Mrs K & 66,6 (Baik) \\
12 & Mrs L & 66,6 (Baik) \\
13 & Mrs M & 83,3 (Sangat Baik) \\
14 & Mrs N & 83,3 (sangat Baik) \\
15 & Mrs O & 83,3 (Sangat Baik) \\
\hline
\end{tabular}

Berdasarkan tabel 4.3 dapat dilihat bahwa perilaku pedagang jelly ada 7 yaitu Mrs A, Mrs C, Mrs D, Mrs E, Mrs M, Mrs $N$ dan Mrs O yang memiliki perilaku sangat baik dengan prosentase 83,3 \%. Hal ini dikarenakan dari item perilaku yang tersedia dalam kuesioner pedagang tidak melihat label, komposisi, serta tanggal kadaluarsa yang tertera pada zat pewarna makanan dengan alasan pedagang tersebut tidak menggunakan tambahan zat pewarna.

Kemudian 5 pedagang yaitu Mrs F, Mrs G,Mrs I, Mrs K dan Mrs L memiliki perilaku baik dengan prosentase 66,6 \%. Hal ini dikarenakan dari item perilaku yang tersedia dalam kuesioner pedagang atau keluarga tidak mengkonsumsi jajanan jelly yang diproduksi dengan alasan akan mengurangi omset pedagang serta tidak melihat label, komposisi, serta tanggal kadaluarsa yang tertera pada zat pewarna makanan dengan alasan pedagang tersebut tidak menggunakan tambahan zat pewarna.

Ada 2 pedagang yaitu Mrs B dan Mrs $\mathrm{H}$ memiliki perilaku cukup dengan prosentase $50 \%$. Hal ini dikarenakan Mrs B dari item perilaku yang tersedia dalam kuesioner pedagang atau keluarga tidak mengkonsumsi jajanan jelly yang diproduksi dengan alasan akan mengurangi omset pedagang, pedagang menggunakan zat pewarna untuk bahan tambahan jajanan jelly serta tidak melihat label, komposisi, serta tanggal kadaluarsa yang tertera pada zat pewarna makanan. Kemudian Mrs $\mathrm{H}$ dari item perilaku yang tersedia dalam kuesioner pedagang menggunakan zat pewarna untuk bahan tambahan jajanan jelly, pedagang menggunakan pewarna sintetis serta tidak melihat label, komposisi, serta tanggal kadaluarsa yang tertera pada zat pewarna makanan.

Sisanya 1 pedagang yaitu Mrs $\mathrm{J}$ memiliki perilaku kurang dengan prosentase $\leq 39 \%$. Hal ini dikarenakan dari item perilaku yang tersedia dalam kuesioner pedagang tidak mengkonsumsi jajanan jelly yang diproduksi dengan alasan akan mengurangi omset pedagang, pedagang menggunakan zat pewarna untuk tambahan jajanan jelly yang diproduksi, pedagang menggunakan zat pewarna sintetis untuk tambahan jajanan jelly yang diproduksi dan tidak melihat label, komposisi, serta tanggal kadaluarsa yang tertera pada zat pewarna makanan yang digunakan.

Sebaiknya pedagang dengan perilaku cukup bahkan kurang harus meningkatkan perilakunya menjadi lebih baik atau sangat baik sehingga makanan jajanan yang ia jual lebih berkualitas dan tidak membahayakan kesehatan orang lain.Kurangnya kesadaran pedagang tentang bahaya yang dapat ditimbulkan dari mengkonsumsi bahan tambahan yang dilarang menjadi alasan yang menyebabkan masih banyaknya bahan tambahan yang telah dilarang tetapi tetap digunakan oleh pedagang (Alsuhendra \& Ridawati, 2013).

\begin{tabular}{|c|c|c|c|}
\hline No & $\begin{array}{l}\text { Nama } \\
\text { Pedagang }\end{array}$ & $\begin{array}{l}\text { Ketersediaan } \\
\text { Pewarna Sintetis }\end{array}$ & Zat \\
\hline 1 & Mrs A & Mudah & \\
\hline 2 & Mrs B & Mudah & \\
\hline 3 & Mrs C & Mudah & \\
\hline 4 & Mrs D & Mudah & \\
\hline 5 & Mrs E & Tidak Mudah & \\
\hline 6 & Mrs F & Tidak Mudah & \\
\hline 7 & Mrs G & Tidak Mudah & \\
\hline 8 & Mrs H & Mudah & \\
\hline 9 & Mrs I & Tidak Mudah & \\
\hline 10 & Mrs J & Mudah & \\
\hline 11 & Mrs K & Tidak Mudah & \\
\hline 12 & Mrs L & Tidak Mudah & \\
\hline 13 & Mrs M & Tidak Mudah & \\
\hline 14 & Mrs N & Tidak Mudah & \\
\hline 15 & Mrs O & Tidak Mudah & \\
\hline
\end{tabular}

Berdasarkan tabel 4.4 dapat dilihat bahwa 6 pedagang yaitu Mrs A, Mrs B, Mrs C, Mrs D, Mrs H 
dan Mrs J mudah memperoleh zat pewarna sintetis dikarenakan jarak untuk mendapatkan zat pewarna sintetis tersebut lebih mudah dibandingkan dengan 9 pedagang lainnya. Dilihat dari hasil tersebut sebaiknya pihak dinas kesehatan lebih mengawasi pedagang-pedagang yang menjual zat pewarna sintetis sehingga penggunaannya sesuai dengan fungsinya. Menurut Teori Lawrence Green dalam Notoatmojo (2007) Enabling factors (faktor pemungkin) dapat terwujud dalam tersedia atau tidak tersedianya fasilitas-fasilitas atau sarana-sarana yang menjadikan suatu hal dapat terwujud dan dalam hal ini ketersediaan zat pewarna sintetis memungkinkan pedagang menggunakan zat pewarna sintetis yang tidak diizinkan tersebut kedalam makanan jajanan yang ia jual.

Tabel 4.5 Penyuluhan Terhadap Pedagang Jelly

\begin{tabular}{lll}
\hline No & Nama Pedagang & Penyuluhan (\%) \\
\hline 1 & Mrs A & 60 (Baik) \\
2 & Mrs B & 60 (Baik) \\
3 & Mrs C & 80 (Sangat Baik) \\
4 & Mrs D & 60 (Baik) \\
5 & Mrs E & 60 (Baik) \\
6 & Mrs F & 60 (Baik) \\
7 & Mrs G & 60 (Baik) \\
8 & Mrs H & 60 (Baik) \\
9 & Mrs I & 60 (Baik) \\
10 & Mrs J & 60 (Baik) \\
11 & Mrs K & 60 (Baik) \\
12 & Mrs L & 60 (Baik) \\
13 & Mrs M & 60 (Baik) \\
14 & Mrs N & 60 (Baik) \\
15 & Mrs O & 60 (Baik) \\
\hline
\end{tabular}

Berdasarkan tabel 4.5 dapat dilihat bahwa ada 1 pedagang yaitu Mrs C mendapatkan penyuluhan dengan sangat baik prosentasenya 80 \% sedangkan lokasi lain mendapatkan penyuluhan dengan baik prosentasenya 60 \%. Hal ini dikarenakan belum maksimalnya penyuluhan yang dilakukan oleh petugas kesehatan sehingga hanya 1 pedagang yang mendapatkan penyuluhan sangat baik. Menurut Teori Lawrence Green dalam Notoatmojo (2007) Reinforcing factors(faktor penguat) dapat terwujud dalam sikap dan perilaku petugas kesehatan atau petugas lain yang merupakan kelompok referensi dari perilaku masyarakat. Dalam hal ini penyuluhan yang dilakukan petugas kesehatan dapat berdampak baik untuk masyarakat jika petugas kesehatan tersebut selalu melakukan penyuluhan tentang zat pewarna sintetis secara berkala kepada pedagang agar dapat diterapkan dalam makanan jajanan jelly yang ia jual.

Beberapa faktor penyebab makanan menjadi berbahaya yaitu kurangnya sosialisasi atau penyuluhan tentang dosis, manfaat, dan bahaya akibat penggunaan bahan tambahan makanan yang dilarang (Cahyo saparinto dan Diana hidayati, 2006).

Tabel 4.6 Pengawasan Yang Dilakukan Puskesmas atau Dinas Kesehatan

\begin{tabular}{lll}
\hline No & Nama Pedagang & Pengawasan (\%) \\
\hline 1 & Mrs A & 60 (Baik) \\
2 & Mrs B & 60 (Baik) \\
3 & Mrs C & 80 (Sangat Baik) \\
4 & Mrs D & 60 (Baik) \\
5 & Mrs E & 60 (Baik) \\
6 & Mrs F & 60 (Baik) \\
7 & Mrs G & 60 (Baik) \\
8 & Mrs H & 60 (Baik) \\
9 & Mrs I & 60 (Baik) \\
10 & Mrs J & 60 (Baik) \\
11 & Mrs K & 60 (Baik) \\
12 & Mrs L & 60 (Baik) \\
13 & Mrs M & 60 (Baik) \\
14 & Mrs N & 60 (Baik) \\
15 & Mrs O & 60 (Baik) \\
\hline
\end{tabular}

Berdasarkan tabel 4.6 dapat dilihat bahwa ada 1 lokasi yang mendapatkan pengawasan sangat baik dengan prosentase 80 \% yaitu di lokasi tempat Mrs C berjualan sedangkan lokasi lainnya mendapatkan pengawasan baik dengan prosentase $60 \%$. Hal ini dikarenakan kurang maksimalnya pengawasan yang dilakukan oleh petugas kesehatan serta pengawasan hanya diadakan 1 tahun 2x.

Menurut Teori Lawrence Green dalam Notoatmojo (2007) Reinforcing factors (faktor penguat) dapat terwujud dalam sikap dan perilaku petugas kesehatan atau petugas lain yang merupakan kelompok referensi dari perilaku masyarakat. Dalam hal ini pengawasan yang dilakukan petugas kesehatan dapat berdampak baik untuk masyarakat jika petugas kesehatan tersebut selalu melakukan pengawasan tentang zat pewarna sintetis secara berkala kepada pedagang agar makanan jajanan jelly yang ia jual terjamin kualitasnya.

Tabel 4.7 Hasil Pemeriksaan Rhodamin B Secara

\begin{tabular}{|c|c|c|c|}
\hline No & $\begin{array}{l}\text { Nama } \\
\text { Sampel }\end{array}$ & Warna & Hasil \\
\hline 1 & Jelly 01 & $\begin{array}{c}\text { Merah } \\
\text { Mencolok }\end{array}$ & Negatif \\
\hline 2 & Jelly 02 & $\begin{array}{c}\text { Merah } \\
\text { Mencolok }\end{array}$ & Positif \\
\hline 3 & Jelly 03 & Merah & Negatif \\
\hline 4 & Jelly 04 & Merah & Negatif \\
\hline 5 & Jelly 05 & Merah & Negatif \\
\hline 6 & Jelly 06 & Merah & Negatif \\
\hline 7 & Jelly 07 & Merah & Negatif \\
\hline
\end{tabular}




\begin{tabular}{|c|c|c|c|}
\hline 8 & Jelly 08 & $\begin{array}{c}\text { Merah } \\
\text { Mencolok }\end{array}$ & Positif \\
\hline 9 & Jelly 09 & Merah & Negatif \\
\hline 10 & Jelly 10 & $\begin{array}{c}\text { Merah } \\
\text { Mencolok }\end{array}$ & Positif \\
\hline 11 & Jelly 11 & Merah & Negatif \\
\hline 12 & Jelly 12 & Merah & Negatif \\
\hline 13 & Jelly 13 & Merah & Negatif \\
\hline 14 & Jelly 14 & Merah & Negatif \\
\hline 15 & Jelly 15 & Merah & Negatif \\
\hline
\end{tabular}

Jelly merupaan salah satu makanan yang cukup digemari oleh masyarakat, Menurut Wibowo (2005) untuk menilai mutu suatu makanan ada 5 parameter sensoris utama yang perlu dinilai, yaitu penampakan, warna, bau, rasa dan tekstur.

Penelitian yang dilakukan hanya meneliti 1 parameter yaitu warna, dengan kriteria warna jelly berwarna merah mencolok. Warna mencolok biasanya mengindikasikan bahwa sampel tersebut ada kemungkinan mengandung zat pewarna sintetis seperti rhodamin $B$, oleh karena itu perlu adanya pemeriksaan lanjut ke laboratorium.

Penggunaan makanan dan minuman yang aman telah diatur oleh pemerintah. Hal ini dibuat dengan tujuan agar bahan makanan yang beredar terutama pewarna makanan yang digunakan memenuhi persyaratan mutu kesehatan.

Berdasarkan hasil pemeriksaan rhodamin $B$ secara organoleptik pada jelly ada 4 sampel jelly yang berwarna merah mencolok yaitu jelly 01 , jelly 02, jelly 08dan jelly 10namun hanya ada 3 sampel yang positif Rhodamin $B$ yaitu jelly 02 , jelly 08 dan jelly 10. Organoleptik merupakan pengujian dengan menggunakan indera manusia sebagai alat utama untuk pengukuran daya penerimaan terhadap produk. Panelis atau penilai dalam uji organoleptik sangat mudah dipengaruhi kondisi fisik dan mentalnya, karena itu perlu sarana dan prasarana yang memadai yaitu prasarana utama meliputi tempat yang tenang, serius tetapi tetap santai agar panelis dapat berkonsentrasi. Sarana meliputi ruang uji dan ruang tunggu panelis. Uji organoleptik memiliki kelebihan dan kelemahan. Kelebihan uji organoleptik yaitu cukup mudah dan cepat dilakukan sehingga hasil cepat diperoleh. Kelemahan uji organoleptik yaitu manusia merupakan panelis yang kadang-kadang dapat dipengaruhi oleh kondisi fisik dan mental sehingga dapat menjadi jenuh dan menurun kepekaannya. Selain itu dapat pula terjadi salah komunikasi antara manajer dan penelis (Soekarto S.T, 2002).

\section{Kesimpulan}

Berdasarkan hasil penelitian dan pembahasan tentang Penggunaan Zat Pewarna Sintetis Rhodamin $B$ Pada Makanan Jajanan Jelly yang Dijual Di Sekolah Dasar Negeri Kecamatan Taman Kabupaten Pemalang, diperoleh simpulan sebagai berikut :

1. Hasil Pemeriksaan Rhodamin B di Laboratorium Berdasarkan hasil pemeriksaan Rhodamin $B$ dari 15 sampel jelly didapatkan 3 sampel positif rhodamin $B$ dan 12 sampel negatif rhodamin $B$.

2. Faktor-faktor yang mempengaruhi para penjual bebas menjual makanan jajanan jelly yang mengandung zat pewarna yang tidak diperbolehkan untuk makanan jajanan di Sekolah Dasar Negeri di Kecamatan Taman Kabupaten Pemalang

a. Pengetahuan

Berdasarkan hasil wawancara dan observasi yang telah dilakukan dengan menggunakan kuesioner dari 15 pedagang jelly ada 3 pedagang yang memiliki pengetahuan sangat baik, 5 pedagang memiliki pengetahuan baik dan 7 pedagang memiliki pengetahuan cukup.

b. Perilaku

Berdasarkan hasil wawancara dan observasi yang telah dilakukan dengan menggunakan kuesioner dari 15 pedagang jelly ada 7 pedagang yang memiliki perilaku sangat baik, 5 pedagang memiliki perilaku baik, 2 pedagang memiliki perilaku cukup dan 1 pedagang memiliki perilaku kurang.

c. Ketersediaan zat pewarna sintetis

Berdasarkan hasil wawancara dan observasi yang telah dilakukan dengan menggunakan kuesioner dari 15 pedagang jelly diperoleh hasil 6 pedagang mudah memperoleh zat pewarna sintetis dan 9 pedagang lainnya tidak mudah memperoleh zat pewarna sintetis.

d. Penyuluhan

Berdasarkan hasil wawancara dan observasi yang telah dilakukan dengan menggunakan kuesioner dari 15 pedagang jelly ada 1 pedagang yang mendapatkan penyuluhan sangat baik dan 14 pedagang lainnya mendapatkan penyuluhan baik.

e. Pengawasan

Berdasarkan hasil wawancara dan observasi yang telah dilakukan dengan menggunakan kuesioner dari 15 lokasi pedagang jelly ada 1 lokasi yang mendapatkan pengawasan sangat baik dan 14 lokasi lainnya mendapatkan pengawasan baik. 
3. Hasil pemeriksaan secara organoleptik dari 15 sampel jelly yang diteliti berjumlah 15 sampel jelly berwarna merah dan merah mencolok 3 sampel terindikasi adanya zat pewarna sintetis rhodamin $B$ dan 12 sampel tidak terindikasi adanya zat pewarna sintetis rhodamin $B$.

Sebaiknya masyarakat terutama orangtua menasihati anak-anaknya agar lebih berhati-hati dalam membeli makanan jajanan terutama jelly yang warnanya mencolok dan jika masyarakat ingin memeriksa ada tidaknya zat pewarna sintetis yang berbahaya khususnya rhodamin B tanpa harus melalui uji laboratorium maka masyarakat bisa menggunakan indicator strip khusus pemeriksaan rhodamin B.

Sebaiknya pedagang mengurus perijinan dagang ke Dinkes sehingga dagangan yang ia jual mendapat pengawasan dan hal itu akan membuat pedagang lebih memperhatikan dagangannya.

Sebaiknya petugas kesehatan baik dari Dinas Kesehatan maupun Puskesmas memberikan penyuluhan tentang zat pewarna berbahaya rhodamin $B$ tidak hanya saat ditemukan sampel yang positif rhodamin $B$ tetapi dilakukan secara berkala dan meningkatkan pengawasan terhadap mutu makanan. Kemudian petugas kesehatan sebaiknya menertibkan pedagang yang belum memiliki ijin dagang dengan memberikan peringatan dalam jangka waktu tertentu dan jika pedagang tersebut belum juga mengurus surat ijin dagang maka alangkah baiknya petugas kesehatan memberikan hukuman kepada pedagang tersebut. Selain itu sebaiknya pedagang yang terbukti menjual jajanan yang mengandung bahan berbahaya khususnya zat pewarna sintetis rhodamin B diberi hukuman tertentu dari Dinas Kesehatan.

Sebaiknya pihak sekolah memberikan pengertian kepada murid-muridnya agar lebih berhati-hati dalam membeli jajanan terutama jajanan jelly dan sebaiknya pihak sekolah memberi peraturan untuk pedagang yang berjualan di lingkungan sekolah harus mempunyai ijin dari Dinas Kesehatan.

\section{Ucapan Terima Kasih}

Terimakasih kepada orangtua saya yang telah mendoakan serta memberikan dana penelitian sehingga penelitian ini dapat terlaksana dengan baik, terimakasih kepada sahabat-sahabat saya yang selalu mensupport saya hingga penelitian ini dapat terselesaikan dan terimakasih kepada rekan-rekan angkatan 2014 kesehatan lingkungan purwokerto yang selalu memotivasi saya untuk dapat menyelesaikan penelitiannya ini tepat waktu.

\section{Daftar Pustaka}

Abdul Kholiq. 2011. Pengaruh Penggunaan Rosella dan Penambahan Gula Pasir dengan Konsentrasi yang Berbeda Terhadap Mutu Organoleptik dan Kadar Vitamin C Minuman Jelly Rosella. Fakultas Teknik Universitas Negeri Semarang.

Alsuhendra dan Ridawati. 2013. Bahan Toksik dalam Makanan, Bandung: PT Remaja Rosdakarya

Anwar, dkk, "Sanitasi Makanan Dan Minuman Pada institusi Pendidikan Tenaga Sanitasi”, Jakarta : Departemen Kesehatan RI

Arikunto, S \& Jabar. 2004. Evaluasi Program Pendidikan. Jakarta: Bumi Aksara

Arikunto, S \& Jabar. 2004. Evaluasi Program Pendidikan. Jakarta: Bumi Aksara

Arikunto, Suharsimi, Prosedur Penelitian Suatu Pendekatan dan Praktek, Jakarta: Rineka Cipta

Arikunto, Suharsimi. 1984. Dasar-Dasar Evaluasi Pendidikan Yogyakarta: Bina Aksara.

Aris Setiawan. 2011. Studi Penggunaan Zat Pewarna Sintetis Rhodamin B dan Methanil Yellow pada Jajanan yang Dijual Sekitar Sekolah Dasar Negeri Wilayah Kecamatan Kaligondang Kabupaten Purbalingga. Jurusan Kesehatan Lingkungan. Poltekkes Kemenkes Semarang.

Asep Tata Gunawan, Dwi Bayu Karti dan Mawaddah. 2015/2016. Lembar Kerja Praktikum Penyehatan Makanan minuman-A. Jurusan Kesehatan Lingkungan. Poltekkes Kemenkes Semarang

Badan Standarisasi Nasional. SNI 01-751-2006. Bahan Tambahan Pangan. Jakarta

BPOM RI. 2010. Laporan Tahunan. Diakses dari http://www.pom.go.id pada tanggal 10 Desember 2010

Butarbutar S. 2007. Analisa Kandungan Rhodamin B dan Natrium Benzoat pada Cabai Merah yang Dijual di Beberapa Pasar di Kota Medan tahun 2007. Fakultas Kesehatan Masyarakat UniversitasSumatera Utara.

Cahyo Saparinto \& Diana Hidayati. 2006. Bahan Tambahan Pangan. Yogyakarta:Karius

Delgado-Vargas F, Paredes-Lopez O. 2003. Natural Colorants for Food and Nutraceutical Uses. Boca Raton: CRC Pr.

Departemen Kesehatan RI, 2003, Kepmenkes RI Nomor 942/MENKES/SK/VII/2003 tentang Pedoman Persyaratan Hygiene Sanitasi Makanan Jajanan, Jakarta: Depkes RI

Departemen Kesehatan RI, 2007, Dampak dan Penggolongan BTP, Jakarta: Depkes Press

Kementerian Kesehatan. Peraturan Menteri Kesehatan RI No. 321/Menkes/PER?XII/76. 
Jakarta:Direktorat Jenderal Pengawasan Obat dan Makanan

Kementrian Kesehatan. Peraturan Menteri Kesehatan RI Nomor 722/Menkes/PER/IX/88. Jakarta:Direktorat Jendral Pengawasan Obat dan Makanan

Kusmayadi A dan Sukandar D. Food Safety and its Application in Daily Life to Prevent Dangers of Consuming Unsafe foods and promote SPFS Farmer's Health. Diakses dari http://www.fao.org/TC/spfs/indonesia/detail_en .asp?id=954pada tanggal 1 November 2016

Mahindru S.N. 2000. Food Additives. New Delhi: Tata Mc Graw Hill

McCann D et al. 2007. Food Additives and Hyperactive Behaviour in 3-year-old and 8/9year-old Children in The Community: A Randomised, Double-Blinded, PlaceboControlled Trial. Lancet Vol 370

Notoatmodjo, Soekidjo. 2007. Promosi Kesehatan dan Ilmu Perilaku. Jakarta: Rineka Cipta

Nurheti Yuliarti, 2007, Bahaya Dibalik Lezatnya Makanan, Yogyakarta: C.V Andi Offset

Peraturan Mentri Kesehatan Republik Indonesia Nomor 033 Tahun 2012 Tentang Bahan Tambahan Pangan

Peraturan Mentri Kesehatan Republik Indonesia Nomor 1168 Tahun 1999 Tentang Bahan Tambahan Pangan

Peraturan Mentri Kesehatan Republik Indonesia Nomor 304/MENKES/PER/IV/1989 Tentang Persyaratan Kesehatan Rumah Mkanan dan Restoran

Republika, 2006, Pewarna Makanan Yang Aman Untuk Dikonsumsi. Diakses dari http://www.republika.co.idpada tanggal 2 November 2016 jam 09:00

Soekarto, S.T. 2002. Penilaian Organoleptik untuk Industri Pangan dan Hasil Pertanian. Bhratara Karya Aksara. Jakarta

Sri Dian Pratiwi. 2014. Identifikasi Penambahan Zat Pewarna Sintetis Rhodamin B dan Methanil Yellow pada Jelly yang Dijual Di Pasar Wage Kecamatan Purwokerto Timur Kabupaten Banyumas. Jurusan Kesehatan Lingkungan. Poltekkes Kemenkes Semarang

Suseno. 2005. Zat Pewarna Makanan dan Minuman. Diakses dari http://www.kebutuhanmanusia.com pada 2 November 2016 jam 10:33

Undang-undang Republik Indonesia Nomer 36 Tahun 2009 Tentang Kesehatan, Jakarta: Presiden Republik Indonesia

Wibowo, S. 2005. Industri Pengasapan Ikan. Yogyakarta: Penebar Swadaya
Winarno F.G, Fardiaz S, Fardiaz D. 1984. Teknologi Pangan. Jakarta: Penerbit PT Gramedia 